\title{
History of Biochemistry at the University of Geneva \\ From the Boulevard des Philosophes to Quai Ernest-Ansermet
}

\author{
Jacques Deshusses and Howard Riezman*
}

\begin{abstract}
A brief account of the developments in biochemistry at the Faculty of Science of the University of Geneva is given from its emergence from organic chemistry at the Ancienne Ecole de chimie to today's Department of Biochemistry at the Section de chimie et biochimie.
\end{abstract}

Keywords: Biochemistry at the University of Geneva

\section{Introduction}

Biochemistry is a science that slowly emerged from the field of organic chemistry and initially focused on the chemistry of molecules isolated from living material. At this stage it was called biological chemistry. However, once the major components were analysed chemically, the scientific interest turned to their transformation, in what turned out to be enzymatic reactions, and how diverse biological functions are regulated. Up until the 1960 s, the study of biochemistry was centered on primary metabolism of small molecules, in particular on how energy is produced, stored and the biosynthesis and catabolism of the basic building blocks, amino acids, sugars, lipidic compounds, and nucleotides. However, with the import of physical and genetic techniques that allowed the determination of the structure of DNA and the discovery of the genetic code, the field of biochemistry grew enormously. Biochemists were found distributed in different departments according to their diverse interests, including Molecular Biology, Animal Biology and Plant Biology.
Techniques also changed greatly with time. As long as the interests were basic analyses of the major components of living materials, the methodology was inspired from the chemistry of complex mixtures of organic substances. Isolation and characterization techniques were fundamental to this process. More refined techniques coming from molecular biology later appeared gradually in the different departments, including various types of spectroscopy. Even though the instrumentation was initially relatively simple, the elevated cost of some instruments required collaborations between different laboratories and led to a number of collaborations within and outside of the University.

At the University of Geneva, Biochemistry developed initially in the Faculty of Sciences, however the Faculty of Medicine also had a biochemistry curriculum, more focused on physiological aspects, which justified the original name given to the department, Physiological Chemistry and later changed to Medical Biochemistry. The mention of Biochemistry as a Department at the Medical School subsequently disappeared and developments there will not be discussed here.

\section{Origins}

A pioneer of experimental biochemistry came from an illustrious citizen of $\mathrm{Ge}$ neva, Théodore de Saussure (1767-1845), although he was not a professor at the university. At the end of the 18th century he discovered the role of carbon dioxide and water on plant growth and outlined the basic reaction of photosynthesis. However, many years passed before biochemistry became of interest at the university. Nevertheless, one can cite Amé Pictet (1857-
1937) who dedicated a small amount of his lecture time to chemical biology, toxicology and pharmacology.

The history of biochemistry in Geneva really is tightly linked to the Ancienne Ecole de Chimie, which was located on the Boulevard des Philosophes. This venerable building, inaugurated in 1877 , housed several internationally renowned scientists. Chemistry was highly oriented towards inorganic chemistry, for example the precise determination of atomic weights by de Marignac during the 19th century, and then turned towards analytical chemistry. The weight given to organic chemistry and research on natural products intensified later. One can say that modern biochemistry and enzymology began at the University of Geneva with the arrival of Kurt H. Meyer (1882-1952). He was nominated professor in 1932 and came from IG Farben in Germany due to disagreements concerning the future of the company. Meyer felt that due to the political climate in Nazi Germany it would be impossible for him to obtain an appointment at the Technical University of Berlin. ${ }^{[1]}$ Prof. Meyer's group worked in several areas, but the principle interests of his group centered on natural polymer structures like rubber, cellulose and starch (1940). In this field, he trained a colleague, Prof. van der Wick (1902-1976) who focused especially on the thermodynamic properties of elastic polymers like rubber. Prof. Meyer also studied the properties of semi-permeable membranes and their electrical properties. Studies in the Meyer lab investigated the enzymes hydrolyzing starch, in particular amylase (1940) and phosphorylase (1942). To do this he introduced the first techniques of zone electrophoresis for proteins.

One of Meyer's students, Edmond Fischer, was greatly influenced by Prof. 
Meyer. He finished his thesis on phosphorylase in 1947 and also purified amylase. Edmond Fischer maintained frequent contact even after he pursued his career in Seattle Washington, in the United States. His work on the reversible phosphorylation of proteins earned him the Nobel Prize for Medicine in 1992. An interview with Edmond Fischer describing his years with Kurt H. Meyer also appears in this volume. Roger-Aymon Boissonnas, another student of Prof. Meyer rose to high levels in the scientific hierarchy of the chemical industry in Basel. Boissonnas received his privat-docent in 1950 to give a course on complex sugars and polysaccharides (1950) and then on the chemical synthesis of peptides (1952). Another student of Prof. Meyer, Eric Stein, as we will see below, became professor of biochemistry in Geneva.

Upon the death of Prof. Meyer in April 1952, the University of Geneva appointed Théodore Posternak (1903-1982). He came to Geneva from Basel in 1953 and in certain ways took over the succession of Kurt H. Meyer. A special chair was created for him and his laboratory was called Chimie Biologique et Organique Speciale (BOS) because the section realized the importance of the new science, biochemistry, that was emerging from organic chemistry and that the University of Geneva had a late start in this field. Prof. Posternak became renowned for his elucidation of the three-dimensional structure of myo-inositol when he previously worked in Lausanne. He pursued several lines of research including the synthesis and structure of cyclic molecules of the inositol family and their phosphorylated derivatives, their metabolic fates in yeast and animals, the analysis of inositol-containing lipids. He branched out to studying analogues of cyclic AMP that were membrane permeant and able to act as second messengers in the activation of cellular signaling pathways. Prof. Posternak was not only an excellent sugar chemist, but he also worked on the synthesis of nucleotide derivatives and fungal pigments. His courses were principally focused on metabolism, because the recent insights into structural biology were not yet available. His course was called chimie biologique. The students interested in these phenomena could follow a hybrid curriculum between biology and chemistry (Fig.).

In parallel Prof. Emile Cherbuliez (1891-1985) was chair of Pharmaceutical Chemistry, then Organic Chemistry. He worked on phosphatase (1949), casein (1950) and on the chemical phosphorylation of alcohols (1952). He was also interested in isolation of pharmacologically active substances from plant tissue. When Posternak arrived in Geneva, he took over

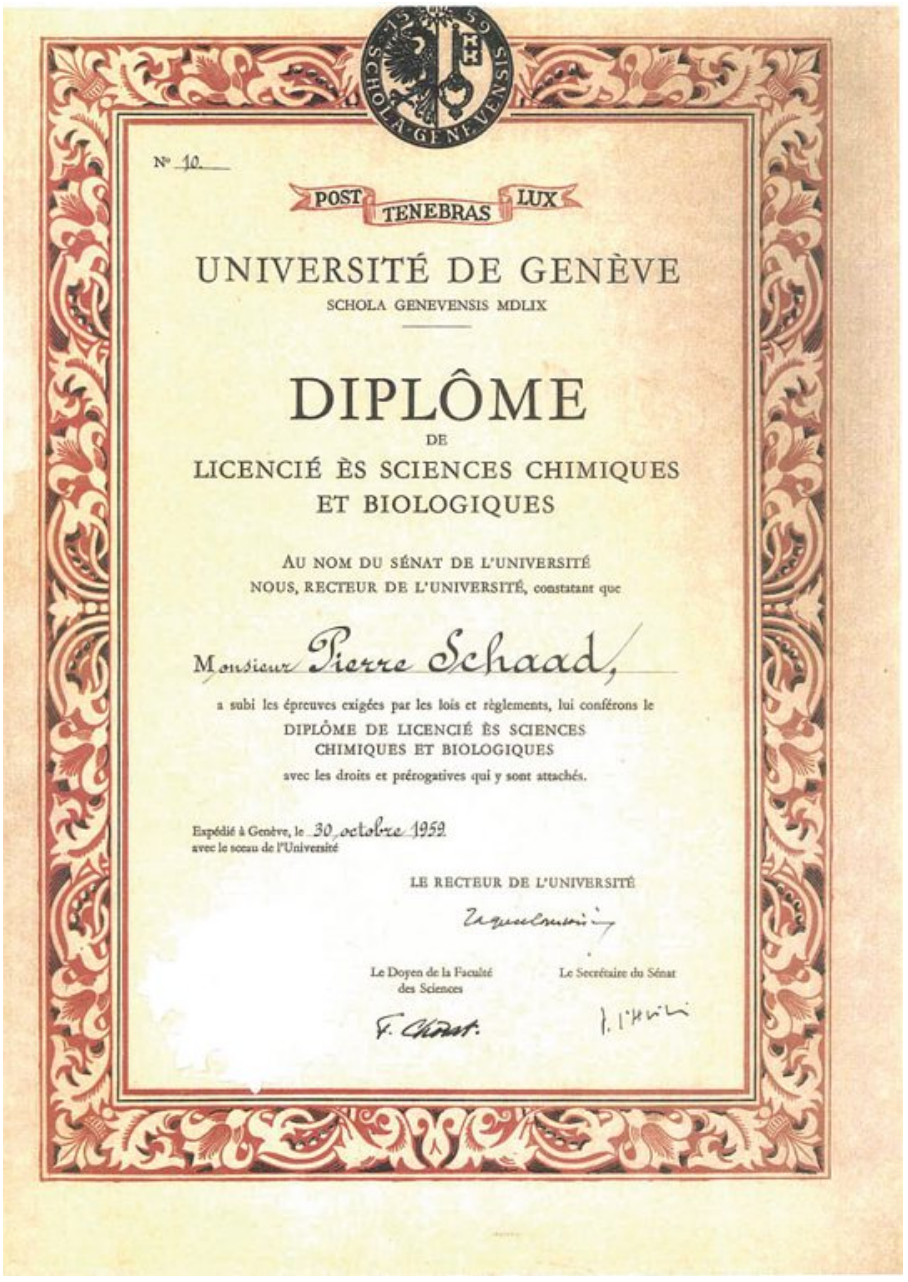

Fig. A copy of a diploma delivered in 1959 before the creation of the department of biochemistry. At the time, a dual degree in chemistry and biology was awarded.

the organic chemistry course that was given for all of the science students.

Starting in 1967 the BOSD (it was called the BOS lab) laboratory was split into different buildings, in Sciences $I$ and the Pavillon des Isotopes, quai ErnestAnsermet, while part remained in the Ancienne Ecole de Chimie. By 1973, the different groups were reunited in a new reorganization when the building Sciences II was opened. The groups of Profs. Stein, Bargetzi and Kobr also moved at the same time into their newly created department, called the Department of Biochemistry.

There were numerous doctorates awarded to people who took over academic or industrial leading positions, among which were: Dominique Reymond (Nestlé, Loréal), Anne-Lise Haenni (professor, Paris, France), Etienne Charollais (professor, Genève, Lausanne), Jacques Deshusses (professor Dept Biochimie, Genève, see below), and Albert Gabai (chemist with Givaudan) among others.

\section{Modern Times}

The biochemistry department finally took form with the opening of the building Sciences II in 1973, where it is still housed today, and the passage of the new university law (see below). However, already in 1966 Eric Stein was nominated for the Biochemistry course given for biologists. Stein also studied with Kurt H. Meyer and worked with Edmond Fischer at the time. They pursued a 15 year-collaboration and life-long friendship. Stein's research was inspired by his postdoctoral work with Prof. Hans Neurath (Nobel prize winner) in Seattle, who also recruited Edmond Fischer to the University of Washington, and was focused on hydrolytic enzymes acting on starch and afterwards on the proteins that bind calcium with high affinity.

Jean-Pierre Bargetzi was nominated professor with his position coming from the Swiss National Science Foundation ad personam. He also spent some time in the laboratory of Hans Neurath and he worked on the structure of collagen as well as enzyme mechanisms. Bargetzi came to Geneva from Neuchatel where he used biochemical methods to study problems in taxonomy.

In 1973 another major change in the university influenced the studies of biochemistry, as well as other disciplines. The new university law changed the structure of the different schools and professors were no longer designated as Chairs with 
the responsibility for a certain course of study, but were nominated in a department that became responsible for teaching. The new university structure led to the creation of the Department of Biochemistry in the Chemistry Section and grouped together the research groups of Profs Stein, Bargetzi, the biological part of the Posternak group and a new lecturer. This new organization was not well accepted by Prof. Posternak who refused to be integrated into the new structure and therefore, he remained head of his own unit until his retirement in 1973. Upon his retirement, his resources were split between the departments of biochemistry and organic chemistry.

As mentioned earlier the university offered a dual diploma in biology and chemistry. In 1969 this dual diploma was replaced with a specific curriculum and diploma in biochemistry. This new diploma quickly became popular with students and approximately one half of the chemistry students chose to do their diploma in biochemistry. This new course of studies also opened the door for a new $\mathrm{PhD}$ in biochemistry, which was offered not only to students in the department, but also to students in other laboratories of the Faculty of Sciences working in the field of biochemistry.

In the mid 1970s, the biochemistry department had the following composition. Jacques Deshusses, professor Assistant (1968), extraordinaire (1971), ordinaire (1975). His research interests encompassed the dynamic aspects of bacterial, yeast and trypanosome membranes. $\mathrm{He}$ studied the mechanism of entry of sugars and amino acids into these organisms and how this related to the energetic state within the cell. As mentioned above JeanPierre Bargetzi arrived from Neuchatel and worked on collagen. Milos Kobr was nominated Assistant Professor in 1968, coming from Purdue University (USA). He studied energy metabolism in the fungus, $\mathrm{Neu}$ rospora crassa with emphasis on the roles of subcellular organelles. He was very interested by the new chemiosmotic theories describing bioenergetics in the cell. As mentioned above, Eric Stein's group focused on calcium binding proteins. The major contributor to these studies was Jos Cox who developed his own group in the department and was nominated Maître d'Enseignement et de Recherche.

In 1980 the Departments of Biochemistry and Molecular Biology decided to join forces and recruited Ulrich K. Laemmli from Princeton (USA), who was appointed professor with a joint appointment in Biochemistry and Molecular Biology. This ushered in a new era where the tools of molecular biology would be used extensively in the biochemistry department. Prof Laemmli is today the most highly cited researcher in the biological sciences and has received several prestigious prizes, among which are the Marcel Benoist Prize and the Louis Jeantet Prize for Medicine. The Laemmli lab began by studying the assembly of phage particles, but since his arrival in Geneva the work has concentrated on the molecular organization and function of the nucleus. More information on Prof Laemmli's research can be found in another chapter in this volume because he is still a member of the current biochemistry department.

Upon the death of Eric Stein, the department recruited Prof. Stuart Edelstein from Cornell University (USA). Prof Edelstein was a successful chairman of the prestigious Section of Biochemistry, Molecular and Cell Biology. He was professor at Cornell from 1977 to 1980 and was called to the Biochemistry Department in 1986, where he acted as director for seven years. His research focused on the structural basis of disease, including seminal work on sickle cell anemia and important work, in collaboration with Jean-Pierre Changeux on the nicotinic acetylcholine receptor. He has received several honors, including election as a foreign member of the French Academy of Sciences and was awarded the Legion d'Honneur in 2003 by the French Prime Minister, Jean-Pierre Raffarin. His most recent work utilizes computational tools to study protein structure and dynamics.

Upon the death of Prof. Kobr, Bernard Fulpius was appointed Professor in 1979 and he also assumed the function of director. Coming from the medical faculty he brought in a more medical vision than the other professors. His work focused on acetylcholine receptors and their recognition by antibodies. His extraordinary talents for administration, however, pulled him away from research. He served on the Research Council of the Swiss National Science Foundation for several years. He became director of the important Louis Jeantet Foundation and eventually the Foundation Brocher. In 1986 he left the department to concentrate on these administrative tasks, becoming Dean of the Faculty of Medicine, then Rector of the University, and was replaced by one of his most talented coworkers, Marc Ballivet, who was appointed professor in 1988. Prof. Ballivet was one of the first to clone the DNA for the acetylcholine receptor and concentrated his future research on this topic. He published over 100 articles in the field and is renowned for his structure-function studies on the receptor. He was department director for two years. Prof. Ballivet retired in 2006. One of his most productive collaborators, Jean-Marc Matter has part of his appointment as a Maître d'enseignement et de recherche in Biochemistry. He does excellent research in neurobiology and participates actively in biochemistry teaching.

In 1992, Dr Patrick Nef, joined the Department of Biochemistry as a START fellow from the Swiss National Science Foundation. After having completed his doctorate in the Biochemistry department in Geneva he did postdoctoral studies at the Salk Institute in San Diego (USA) before returning to Switzerland. His work centered on the molecular mechanisms that regulate the chemosensory response. $\mathrm{He}$ stayed in the department until 1998 and has since been Vice-President and Global Director at Roche Pharma Partnering, and CEO of biotechnologies companies, including Faust Pharmaceuticals and Xytis.

In 1993, F. Gisou van der Goot joined the department, first as a Maître Assistant and then as a Maître d'enseignement et de recherche. She received a $\mathrm{PhD}$ in biophysics from Paris and then was a postdoctoral fellow at the European Molecular Biology Laboratory (EMBL) in Heidelberg. Her work focuses on bacterial pathogenesis with particular emphasis on bacterial toxins and their mechanism of action. After a highly successful period in the Biochemistry department she was appointed Associate Professor in the Faculty of Medicine in Geneva (2001) and then recruited by the EPFL as a full Professor in 2005. She is this year's recipient of the Marcel Benoist Prize.

In 1993, Jean Gruenberg was appointed Professor, as successor of Jean-Pierre Bargetzi. Prof. Gruenberg obtained his doctorate from the department of biochemistry, working in the laboratory of Jacques Deshusses. After postdoctoral studies at the University of California-Riverside (USA) and at the EMBL, he started his own group at the EMBL. The Biochemistry Department recruited him from the EMBL. Together with Prof. Laemmli the two groups clearly reoriented the department towards its current focus, the biochemistry of cell biology and membranes. The Gruenberg group focuses on the study of the pathway of endocytosis, the route whereby growth factors, hormones and their receptors enter into cells. This route is also hijacked by viruses and other pathogens that use it to enter into cells. He is renowned for using in vitro reconstitution of endocytic events in his analysis of the pathway. More information about Prof. Gruenberg's research can be found in this volume as he is still a member of the department. He was director of the department for several years.

In 2002, Howard Riezman was recruited to replace Prof. Jacques Deshusses. Prof. Riezman obtained his PhD from the University of Wisconsin-Madison (USA) and then moved to Switzerland for postdoctoral studies with Prof. Gottfried Schatz at the Biozentrum in Basel. After holding a group leader position for 
five years at the Swiss Experimental Cancer Research Institute (ISREC), he took a professor position in Biochemistry at the Biozentrum in Basel where he stayed for 14 years before being recruited to Geneva. His research focuses on the biochemistry and genetics of membrane trafficking with emphasis on endocytosis and secretion. He is known for his pioneering studies on endocytosis in yeast and the demonstrations that actin, ubiquitination, and certain lipids are required for this process. He served for almost eight years on the Research Council of the Swiss National Science Foundation. $\mathrm{He}$ is the current department director.

In 2004, Thierry Soldati joined the department as a Maître d'enseignement et de recherche and in 2009 became the official successor of Jos Cox in this position. Dr. Soldati was an undergraduate student in the department of biochemistry and then went to the ETH Zürich for his doctorate. After a postdoctoral stay at Stanford (USA) he was group leader at the Max Planck Institute in Heidelberg (Germany) then lecturer at the Imperial College London (UK) from where he was recruited to Geneva. His research exploits the social amoeba Dictyostelium discoideum as a model system for studies on phagocytosis and bacterial infections, in particular mycobacteria.

The increasing importance of Biochemistry at the University as well as the increasing interactions with Molecular Biology are revealed by the most recent events. In 2008, the Section of Chemistry changed its name to be called the Section of Chemistry and Biochemistry.
The increased interactions between Biochemistry and Molecular Biology is reflected in two of the recent appointments leading to the current composition of the department. Professors Ballivet and Laemmli were replaced by two jointly appointed professors. This doubled the number of joint appointments.

Prof. Thanos Halazonetis is a Greek citizen trained originally in dentistry, but who obtained his $\mathrm{PhD}$ in genetics from Harvard. He worked three years at Merck Sharp and Dohme before taking a faculty position at the Wistar Institute where he climbed the ranks from Assistant to Full Professor. In 2006 he was recruited to the University of Geneva. His laboratory is housed in the Department of Molecular Biology, which moved a few years ago from Sciences II to the newly finished Sciences III next door. His research centers on the biochemistry of DNA repair and the role of DNA damage in cancer.

Prof. Marcos González-Gaitán is a Spanish citizen who received his $\mathrm{PhD}$ in Biology from the Autonomous University of Madrid, where he stayed as a postdoctoral fellow afterwards. He then was a postdoctoral fellow in Munich and the Max Planck Institute for Biophysical Chemistry in Göttingen before becoming a group leader at the Max Planck Institute of Molecular Cell Biology and Genetics in Dresden (Germany). In 2006 he was recruited from Dresden to the University of Geneva. His laboratory is housed in the biochemistry department. His research focuses on the mechanisms of signal transduction in model systems, including Drosophila and zebrafish, in particular how membrane trafficking and signaling are interrelated and how they affect developmental decisions.

Finally, in 2007, Reika Watanabe was appointed Assistant Professor in the department of biochemistry. Prof Watanabe received her $\mathrm{PhD}$ from Osaka University and then was a postdoctoral fellow with Prof. Riezman in Basel then Geneva. Since 2007 she is a Professeure Boursière of the Swiss National Science Foundation. The focus of her research is on the mechanism of protein exit from the endoplasmic reticulum and protein secretion in animal cells.

Over the past two decades the Biochemistry department has made a constant effort to attract the highest quality researchers possible and focus on using biochemical and genetic techniques to elucidate the mechanisms of basic cell biological processes. These have been fruitful years and more information can be found about the current focus and productivity of the department in the accompanying article in this volume, with a more detailed explanation of the research of all of the current members.

Received: October 27, 2009

[1] 'The Expulsion of Jewish Chemists and Biochemists from Academia in Nazi Germany', Perspectives on Science 1999, 7, 1-86. 